\title{
Lymph node staging in prostate cancer: perspective for the pathologist
}

\author{
Susan Prendeville, Theodorus H van der Kwast
}

Department of Pathology, Laboratory Medicine Program, University Health Network, Toronto, Ontario, Canada

\section{Correspondence to} Dr Susan Prendeville, Department of Pathology, University Health Network, 11th Floor, Eaton Wing, Toronto General Hospital, 200 Elizabeth Street, Toronto, Ontario, Canada M5G 2C4; susan.prendeville@uhn.ca

Received 12 July 2016 Accepted 30 July 2016 Published Online First 23 August 2016
CrossMark

To cite: Prendeville $S$, van der Kwast TH. J Clin Pathol 2016;69:1039-1045.

\section{ABSTRACT}

Pelvic lymph node dissection (PLND) currently represents the gold standard method for nodal staging in the setting of localised prostate cancer and may also have a therapeutic benefit in certain patients. The histopathological evaluation of PLND specimens plays a critical role in accurate lymph node staging, however there is currently a lack of consensus regarding the optimum approach and no quality parameters are in place. In addition, there are no guidelines as to the handling of less commonly encountered nodal specimens such as those identified within the anterior fat pad. This summary provides an overview of pertinent issues regarding lymph node staging in prostate cancer, with a focus on the histopathological evaluation of resected nodal specimens. We hope that this review will further the discussion on how to achieve a more standardised approach to the processing and reporting of PLND specimens in the setting of prostate cancer.

\section{INTRODUCTION}

Pelvic lymph node dissection (PLND) is currently the most reliable method for nodal staging in prostate cancer. ${ }^{1}$ Lymph node (LN) status following PLND provides important prognostic information and is used to guide clinical decisions regarding adjuvant treatment. ${ }^{1-5}$ In addition, the removal of metastatic deposits at PLND may potentially have therapeutic or even curative benefit in selected patients. $^{67}$

The pathological evaluation of PLND specimens plays an important role in accurate LN staging. Currently, however, there is a lack of consensus regarding the optimal handling of these specimens. The consequent variability in the processing, histological evaluation and reporting of nodal resections may influence the final LN status and subsequent risk stratification of patients. As a result, there are no universally accepted quality parameters available to determine the adequacy of a PLND.

This review outlines salient issues regarding $\mathrm{LN}$ staging in prostate cancer with particular emphasis on the histopathological evaluation of resected nodal specimens.

\section{NODAL STAGING IN PROSTATE CANCER AND PATIENT SELECTION FOR PLND}

LN status is an important prognostic indicator of outcome in patients undergoing radical prostatectomy for localised prostate cancer. ${ }^{8-10}$ The risk of LN metastases in an individual patient can be estimated using preoperative nomograms, which are based on a number of clinical and pathological parameters such as prostate specific antigen (PSA) level, clinical stage, biopsy Gleason Score and the number of positive cores at biopsy. ${ }^{11-14}$

The current European Association of Urology guidelines recommend PLND for all high-risk patients, as well as intermediate-risk patients when the nomogram-based predicted risk of $\mathrm{LN}$ involvement is $>5 \% .^{1}$

For patients at risk of $\mathrm{LN}$ metastasis, bilateral PLND remains the gold standard procedure. However, the optimal anatomical extent of PLND has been the subject of debate. Standard PLND generally consists of removal of all nodal tissue anteromedial to the external iliac vein and from within the obturator fossa. ${ }^{15} \mathrm{~A}$ number of studies have demonstrated increased LN yield and detection of metastases with an extended PLND template. ${ }^{15-20}$ As a result, extended PLND is currently the standard of care recommended in all patients for whom nodal staging is indicated. ${ }^{1}$ This involves the removal of LNs overlying the external iliac artery and vein, within the obturator fossa, as well as medial and lateral to the internal iliac artery. ${ }^{1} 15$ The common iliac and presacral areas may also be resected as part of the extended PLND template, as there is evidence that this improves nodal staging. 12122

In view of the risk of complications and morbidity following an extended PLND there is an interest in alternative, less invasive methods of nodal staging. The concept of sentinel lymph node (SLN) dissection in prostate cancer was first described by Wawroschek et al in 1999. ${ }^{23}$ Since then a number of studies have investigated the utility of SLN mapping to guide PLND in prostate cancer and potentially reduce the extent of dissection, although the procedure is regarded as experimental at this stage. ${ }^{124} \mathrm{~A}$ recent review of the literature reported that SLNs were identified outside of the dissection template for an extended PLND in 4.1$25 \%$ of cases, and of patients with positive LNs $3.5-17 \%$ had SLN metastases outside of the extended PLND field. ${ }^{25}$ These findings highlight the potential for SLN mapping to improve nodal staging. However, the procedure is limited by falsenegative results, particularly in high-risk patients, which may occur due to the obstruction of lymphatic channels by tumour. ${ }^{26}$ It has been proposed to combine SLN guided LN dissection with extended PLND to optimise staging ${ }^{25}$ although this may represent an excessive dissection for many patients. ${ }^{27}$ Due to these limitations, SLN sampling is not currently recommended for nodal staging of patients with prostate cancer, however the future potential of this technique is an area of ongoing research.

Imaging studies such as abdominal computed tomography (CT) and multiparametrical MRI may 
be useful for nodal staging when there is gross $\mathrm{LN}$ involvement, however they lack sensitivity for the detection of microscopic LN metastases. ${ }^{1}{ }^{28}$ Newer imaging techniques such as 11C-choline or $18 \mathrm{~F}$-choline positron emission tomography (PET)/CT and prostate-specific membrane antigen-PET CT (PSMA PET/CT) are not currently recommended for LN staging. $^{1}$

\section{LN YIELD AT PLND}

One of the key concerns for both the surgeon and the pathologist is what constitutes an adequate PLND in terms of the LN yield. A number of studies have established a relationship between the number of LNs examined at PLND and the rate of metastatic disease detection ${ }^{18} 2930$ and this partly underpins the rationale for performing an extended PLND in all patients. As a result, the LN yield is often used as a surrogate marker for the completeness of surgical dissection and, by analogy, it's adequacy for accurate staging. Despite this, there are currently no guidelines as to the median number of LNs that should be examined following a PLND for prostate cancer. This is in contrast to many other organ sites where such recommendations have been established.

Individual studies have attempted to address this question, and a variety of LN counts have been proposed in the literature (table 1). In a cadaver-based study, Weingärtner et $a l^{31}$ sought to identify the normal anatomical LN yield that should be expected from a standard PLND, which comprised all of the nodal tissue from between the internal and external iliac arteries and the obturator fossa. The study included 30 cadavers, where death was not cancer related, as well as 59 patients with prostate cancer. Based on their findings, they proposed $20 \mathrm{LNs}$ as a guideline estimate for a standard PLND, however they reported marked interindividual variation, with the number of LNs retrieved in an individual case ranging from 8 to 56. Similarly, another cadaveric study designed to examine the LN yield at PLND performed for urothelial carcinoma, also found a significant variation in LN counts between individuals. ${ }^{32}$

Others have correlated the rate of $\mathrm{LN}$ metastasis with the number of nodes retrieved in an attempt to establish the minimum yield required for accurate staging. Barth et al recommended examination of at least 13 LNs from a standard PLND, based on their study of 283 patients where the rate of LN metastasis more than doubled when $>12 \mathrm{LNs}$ were examined. ${ }^{30}$ In a larger series where the majority of patients underwent an extended PLND, Briganti et al reported that the ability to detect $\mathrm{LN}$ involvement was close to zero when $<10$ LNs were retrieved and $>90 \%$ when $>28$ LNs were examined. ${ }^{19}$ Similarly, a population-based study of 20789 cases identified using the Surveillance, Epidemiology, and End Results database found that examination of $20 \mathrm{LNs}$ should allow accurate staging in $>90 \%$ of $_{\text {cases. }}{ }^{30}$

Recently, Kluth et $a l^{33} 34$ developed predictive models to assess the minimum number of LNs required for accurate staging in an individual patient based on tumour characteristics in the preoperative or postoperative setting. The authors propose that patients at a higher risk of $\mathrm{LN}$ metastases require examination of a larger number of LNs to accurately predict LN-negative status and this can be used to tailor the extent of PLND. For preoperative risk assessment, they developed their model on a cohort of 4770 patients whose PLND extent was at the discretion of the surgeon and subsequently validated it on 3595 patients who underwent an extended PLND. ${ }^{33}$ Using their model, high-risk patients in the validation cohort required examination of at least $10 \mathrm{LNs}$ to achieve $80 \%$ probability of being truly $\mathrm{LN}$-negative. ${ }^{31}$

One of the key issues when interpreting the literature on this topic is the lack of uniformity between studies, both in terms of the extent of PLND and the method of pathological evaluation. In fact, even the definition of what constitutes an extended PLND varies between studies. Importantly, the LN count is not solely a reflection of the anatomical extent of dissection, but is also influenced by pathological processing methods and individual anatomical variation. The latter variable is clearly illustrated by the marked heterogeneity between individuals seen in anatomical autopsy studies, ${ }^{3132}$ as well as clinical studies where the number of LNs retrieved in an individual case ranged from 1 to 40. ${ }^{18} 2930$ A survey conducted by the International Society of Urological Pathology (ISUP) also found significant variability among genitourinary pathologists in the number of LNs they usually identify. ${ }^{35}$ The majority of pathologists (86\%) reported finding $<10$ LNs on average, with only $8 \%$ and $3 \%$ recording an average $\mathrm{LN}$ yield of $11-15 \mathrm{LNs}$ and $>15 \mathrm{LNs}$, respectively. ${ }^{35}$ Although the extent of PLND among respondents was not known, these findings suggest a lower average LN yield in routine clinical practice when compared with LN counts proposed in the literature. ${ }^{35}$

Based on the heterogeneity of studies in terms of surgical and pathological approaches, in addition to anatomical variation between individuals, it is difficult to define the adequacy of staging using LN yield. Additionally, in some studies, the mean/ median yield across the study cohort was significantly lower than their proposed minimum LN yield, highlighting the current difficulty with applying these thresholds to an individual patient in routine practice (table 1). Importantly, a consistent approach to the pathological handling and evaluation of PLND specimens is required in order to evaluate $\mathrm{LN}$ yield as a quality indicator across institutions. Furthermore, collaboration between surgeons and pathologists is essential to optimise staging and maximise benefit for the patient. For example, submission of PLND zones in separate containers can aid gross pathological assessment, ${ }^{1}{ }^{36}$ while a low nodal yield $<10$ LNs should, in our opinion, always trigger further evaluation of the specimen by the pathologist.

\section{PATHOLOGICAL PROCESSING OF PLND SPECIMENS}

The pathological examination of surgical specimens plays an important role in accurate staging and can influence the final LN count at PLND. Currently, however, there are no established guidelines as to the optimum method of examining PLND specimens, and the approach may vary considerably between individual pathologists and institutions. This is further compounded by a number of practical issues related to the identification and enumeration of individual LNs.

The standard approach to isolating LNs from any surgical specimen is to manually palpate and dissect them from the surrounding fat. Compared with other anatomical sites, however, pelvic LNs are often extensively infiltrated by fat and may have an elongated tortuous configuration, requiring meticulous dissection for accurate counting of LNs. Alternatively, some may prefer to serially slice the intact specimen for ease of tissue submission. This approach, however, makes enumeration of individual LNs very difficult, and is prone to inflation of the LN count due to 'double-counting' of multiple slices from a single LN as separate individual LNs (figure 1). This is particularly true given the fatty and tortuous nature of $\mathrm{LNs}$ at this location. Consequently, careful gross dissection of individual 
Table 1 Comparison of studies with recommendations regarding the expected/required LN yield following PLND for prostate cancer

\begin{tabular}{|c|c|c|c|c|c|c|c|}
\hline \multirow[b]{2}{*}{ Study } & \multirow[b]{2}{*}{ Study type } & \multirow{2}{*}{$\begin{array}{l}\text { No. of } \\
\text { cases }\end{array}$} & \multirow[b]{2}{*}{ Type of PLND } & \multirow{2}{*}{$\begin{array}{l}\text { Method of pathological } \\
\text { assessment }\end{array}$} & \multicolumn{3}{|l|}{ Lymph nodes } \\
\hline & & & & & Mean/median & Range & Recommended \\
\hline Weingärtner et $a l^{31}$ & $\begin{array}{l}\text { Cadaveric and clinical, } \\
\text { single institution }\end{array}$ & $\begin{array}{l}30 \text { cadavers; } \\
59 \text { patients }\end{array}$ & Standard PLND & $\begin{array}{l}\text { Palpable LNs submitted; } \\
\text { xylene clearance used }\end{array}$ & $\begin{array}{l}\text { Cadaver: } \\
\text { 22.7/not given } \\
\text { Patient: } \\
\text { 20.5/not given }\end{array}$ & $\begin{array}{l}\text { Cadaver: } \\
8-56 \\
\text { Patient: } \\
10-37\end{array}$ & 20 \\
\hline Barth et $a l^{29}$ & Clinical, single institution & 283 & Standard PLND & Palpable LNs submitted & Not given/16 & $5-40$ & 13 \\
\hline Briganti et $a l^{18}$ & Clinical, single institution & 858 & $\begin{array}{l}\text { 'Most' had } \\
\text { extended PLND }\end{array}$ & Palpable LNs submitted & $15 / 14$ & $2-40$ & 28 \\
\hline Abdollah et $a^{30}$ & $\begin{array}{l}\text { Clinical, } \\
\text { multi-institutional }\end{array}$ & 20789 & $\begin{array}{l}\text { Heterogeneous } \\
\text { —not specified }\end{array}$ & $\begin{array}{l}\text { Heterogeneous-not } \\
\text { specified }\end{array}$ & $6.4 / 5$ & $1-40$ & 20 \\
\hline
\end{tabular}

LN, lymph node; PLND, pelvic lymph node dissection.

LNs is preferable for accurate LN retrieval. LN revealing solutions have been used to aid the identification of LNs, however experience with these techniques in PLND specimens is limited. ${ }^{37} 38$

Even following careful gross delineation of individual nodes, microscopic counting of LNs is not always straightforward and is dependent on subjective interpretation in certain scenarios. The presence of an architectural framework such as a capsule and subcapsular sinus should be identified to differentiate small LNs from lymphoid aggregates. However, microscopic sections of a single fat-infiltrated LN can yield the appearance of separate LNs, while truly separate small LNs which are not grossly annotated may exist in the fat adjacent to a larger LN. In these cases, the $\mathrm{LN}$ number is open to interpretation and pathologists must exercise their own judgement based on the combination of gross and microscopic features.

All grossly identified LNs should be submitted in their entirety for histological examination, except for those with clearly identifiable metastatic deposits where sampling will suffice. However, following isolation of all palpable LNs, there is currently no consensus regarding the routine evaluation of the remaining fatty tissue, which may contain microscopic, impalpable LNs. ${ }^{35}$ This may be important as a poor correlation between LN size and the presence of metastatic disease has been demonstrated. $^{39}$ Total submission of PLND tissue has been shown to increase the LN yield ${ }^{39} 40$ although the clinical impact and cost-effectiveness of this strategy remains uncertain. In one study, submission of all the remaining tissue following isolation of palpable LNs increased the mean LN yield from 3.8 to 10.8 while requiring an additional 3-5 blocks. ${ }^{40}{ }^{41}$ Metastatic prostate carcinoma was identified in eight cases, including one with a solitary metastasis in an impalpable LN. This suggests that all embedding the tissue may impact the final LN stage in a small number of cases, although the cost: benefit of routinely using this approach has not been established. Montironi et al ${ }^{42}$ proposed the use of large format histology, or mega cassettes, to facilitate complete embedding of PLND specimens to increase nodal yield and detection of metastases. However, specimens in the study were serially sliced and submitted, a technique which can be prone to overestimation of the LN count. The authors identified separate LNs by correlating the microscopic size and contour of individual sections, although this may not be reliable given the often irregular and meandering configuration of LNs at this site. Following isolation of palpable LNs, an ancillary technique such as differential inking could be applied to enable the use of mega cassettes for the examination of multiple LNs. Issues related to the processing, storage and cost of using mega cassettes in this setting may pose limitations and would need to be considered prior to adopting such an approach.

Although there is evidence that total submission of PLND tissue may alter nodal staging in a small number of cases, the data are limited and further study is required to determine if this approach is justified in all cases. Current data sets from the Royal College of Pathologists ${ }^{43}$ and the College of American Pathologists $^{44}$ do not specifically recommend all embedding of PLND specimens. However, the pathologist does have a clear responsibility to ensure a thorough examination of the tissue for accurate staging. All palpable LNs should be carefully isolated and submitted, along with any firm areas which may potentially represent nodal tissue. Serial sectioning of larger nodes along their short axis will increase the surface area examined histologically, while smaller LNs can be bisected. Individual judgement may be used regarding submission of the remaining fat and will be influenced by the amount of fatty tissue present, the number of LNs identified in the specimen and the experience of the prosector examining the specimen. If the tissue is not entirely
Figure 1 Grossly identified fatty lymph node was bisected and counted as one lymph node (A), however with serial slicing this could be interpreted as multiple (up to four) separate lymph nodes (B).
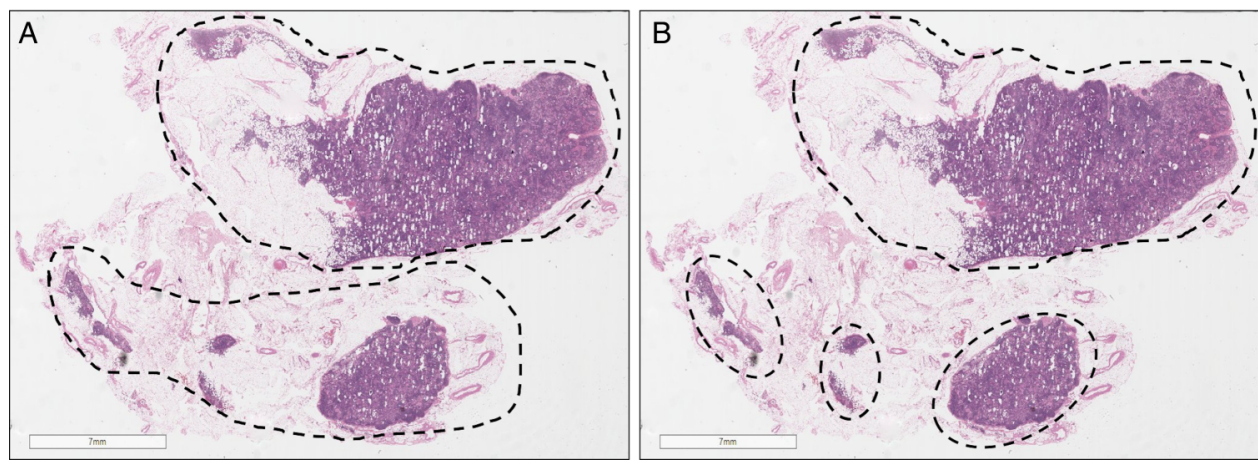
submitted, a low nodal yield following microscopic examination should always prompt the pathologist to examine the gross specimen and consider submission of additional tissue.

Frozen section (FS) analysis of pelvic LNs was previously advocated for intraoperative staging to guide surgical management. ${ }^{45}$ However, evidence that radical prostatectomy confers a significant survival benefit in patients with $\mathrm{LN}$ metastases ${ }^{46} 47$ has made this procedure redundant, and intraoperative FS analysis of pelvic LNs is no longer recommended. ${ }^{1}$

\section{METASTATIC TUMOUR BURDEN AND PROGNOSTIC HISTOPATHOLOGICAL PARAMETERS}

The current (2009) tumour, node, metastases (TNM) cancer staging manual groups all node-positive patients into a single category (pN1). ${ }^{48}$ However, there is evidence that the nodal burden of disease can further stratify patients in terms of prognosis and outcome. Several studies have demonstrated superior long-term outcomes in patients with limited nodal involvement as compared with those with more extensive nodal disease. ${ }^{8} 10$ 49-52 As such, LN-positive patients may be further stratified on the basis of the number of positive LNs, with studies suggesting one or two positive LNs as the cut-off for risk grouping. ${ }^{10} 4950$ This makes careful enumeration of LNs by the pathologist critical, as any sampling method prone to 'doublecounting' may falsely elevate the number of metastatic nodal deposits reported.

Nodal cancer volume, or the size of the largest metastatic tumour deposit, has also been shown to have prognostic significance. ${ }^{53-57}$ In fact, the size of the largest metastatic deposit may be more important than the number of positive LNs. ${ }^{53} 58$ Fleischmann et $a l^{57}$ used a cut-off of $10 \mathrm{~mm}$ for the size of the largest metastasis and found this to be the strongest independent predictor of recurrence-free survival, disease-specific survival and overall survival in their series of 102 patients. As such, there was consensus among genitourinary pathologists at the 2009 ISUP conference that the diameter of the largest metastatic deposit should be routinely evaluated and included in the final pathology report. ${ }^{35}$ This will often comprise a microscopic

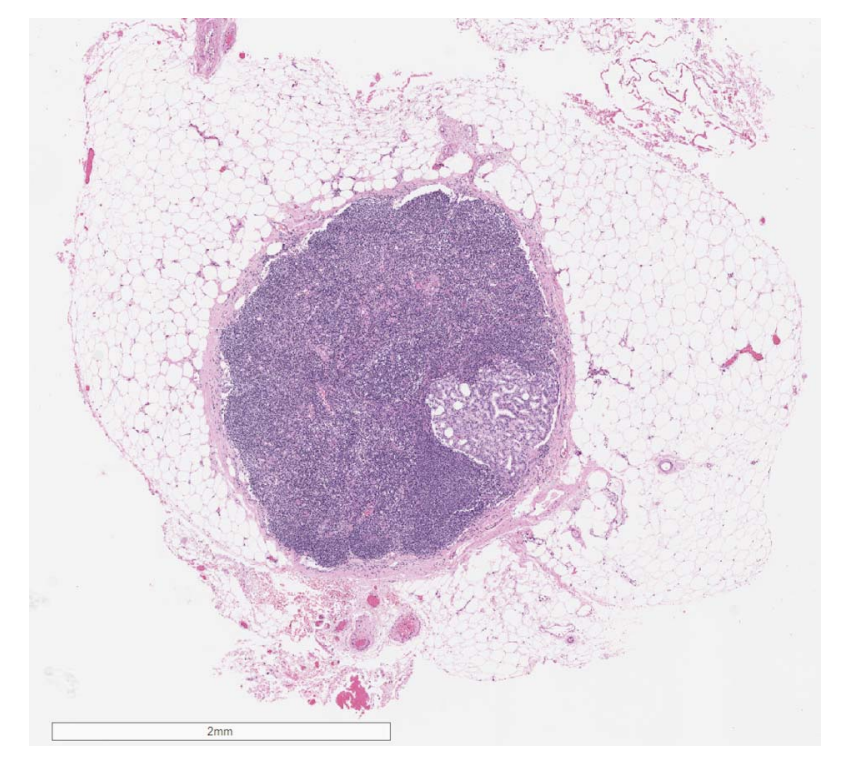

Figure 2 Metastatic tumour in a lymph node identified within the anterior fat pad tissue. This represented the only site of metastasis in the case. measurement, however the gross measurement will be more accurate for large tumour deposits.

A more favourable prognosis for patients with micrometastatic disease has been reported but the definition of micrometastases is not uniform among studies and the term has been applied to tumour deposits of varying sizes. ${ }^{55}$ 57-59 In organs such as the breast, the definition and significance of small metastatic deposits including micrometastases and isolated tumour cells is well established and incorporated into the TNM staging system. ${ }^{48}$ However, in relation to prostate cancer no such definitions exist, and risk grouping based on size is not part of the current staging system.

Extracapsular extension (ENE) of tumour beyond the LN was reported to have prognostic significance in one early study, ${ }^{60}$ however subsequent studies have not found ENE to be an independent prognosticator in patients with prostate cancer with $\mathrm{LN}$ metastases. ${ }^{5-57} 6162$ Similarly, Boormans et $a l^{56}$ found a Gleason Score $>7$ within the LN metastasis to be a predictor of survival. Other studies could not corroborate the independent prognostic value of nodal Gleason Score when controlled for other factors. ${ }^{62} 63$ Consequently, it is not necessary to routinely report these parameters.

\section{HISTOLOGICAL STEP-SECTIONING AND THE USE OF IMMUNOHISTOCHEMISTRY}

As previously discussed, gross sectioning of LNs at short intervals increases the surface area available for histological evaluation to maximise the detection of metastatic deposits. A number of studies have also examined the utility of additional H\&E stained step sections and cytokeratin immunohistochemistry (IHC) as an aid to the identification of small metastatic deposits in pelvic LNs. ${ }^{64-70}$ Engvad et $a l^{64}$ performed extensive step-sectioning and cytokeratin IHC of all LNs in 169 patients initially staged as pN0 following routine pathological examination of the PLND specimens. This resulted in upstaging of five patients $(2.38 \%)$, with metastatic deposits ranging in size from $0.3 \mathrm{~mm}$ to $2.2 \mathrm{~mm}$ (mean $2.2 \mathrm{~mm}$ ) identified on step sections. IHC did not provide additional information. Based on the authors' estimations, the cost of their extended LN evaluation was more than three times the cost of standard processing. In another series of 180 patients initially staged as pN0, occult tumour cells were identified in $13.3 \%$ following the application of IHC, and were associated with decreased survival. ${ }^{65}$ However, most studies have generally reported a low yield in terms of patient upstaging following the application of these ancillary studies. ${ }^{66-69}$ Recently, Kehr et al ${ }^{70}$ did not find any benefit from the use of IHC in patients who had received neoadjuvant hormonal therapy. Overall, given their cost implications, these ancillary techniques do not yield sufficient benefit to justify their routine application in the examination of pelvic LN specimens.

A further area under investigation is the utility of additional molecular techniques to improve the detection of LN metastases. For example, expression of genes such as PSA, PSMA and prostate cancer gene 3 using quantitative real-time reversetranscriptase PCR analysis has been proposed as a useful adjunct in the identification of $\mathrm{LN}$ metastases. ${ }^{71-75}$ At this time, these techniques remain experimental and their utility in clinical practice remains to be established.

\section{LNS WITHIN THE ANTERIOR FAT PAD AND PERIPROSTATIC TISSUE}

The anterior fat pad (AFP) comprises a mass of fibrofatty tissue that is often excised during prostatectomy to facilitate 
visualisation of the surgical anatomy, in particular for dissection of the apex during robotic assisted radical prostatectomy. ${ }^{76} \mathrm{~A}$ number of studies have demonstrated that this fatty tissue may contain LNs, and these can occasionally harbour metastatic disease. ${ }^{77-82}$ Published series have identified LNs in the AFP tissue in $5.5-17 \%$ of cases, with metastatic tumour in $0.94-$ $2.5 \%$ of cases and consequent upstaging in $0.39-2.5 \%$ of cases. These findings were based on entire submission of the AFP tissue in the majority of studies. ${ }^{77-79}$ In most cases, tumours that metastasised to the AFP LNs had intermediate-risk or highrisk features at prostatectomy and were often anteriorly located in the prostate. ${ }^{77-79}$

Currently there are no guidelines regarding the pathological handling of these specimens. Given that LNs within the AFP may occasionally be the only site of metastatic disease, if this tissue is dissected at surgery, it should be routinely submitted for pathological examination (figure 2). Aning $e t \mathrm{al}^{77}$ recommended complete submission of the AFP tissue, as the majority of their specimens could be submitted in three blocks. However, although the median maximum diameter of the AFP specimens in their study was $40 \mathrm{~mm}$, they also had cases measuring up to $115 \mathrm{~mm}$, which would require a larger number of blocks for total embedding. Conversely, other studies have suggested limiting the pathological examination of AFP tissue to patients with intermediate-risk or high-risk features. ${ }^{80}{ }^{81}$ We propose examination of AFP tissue similar to PLND specimens, with isolation and submission of all palpable LNs.

Infrequently, LNs are also found in periprostatic fat, particularly around the base and seminal vesicles, and they are mostly detected incidentally when examining histological sections of the prostate. ${ }^{83-85}$ For example, Deng et al ${ }^{83}$ found periprostatic LNs in $0.8 \%$ of 2663 radical prostatectomies, with $0.3 \%$ of cases harbouring metastatic tumour. Given the current single category staging system, patients with metastases to AFP or periprostatic $\mathrm{LNs}$ are staged as $\mathrm{pN} 1$, however their clinical significance in isolation has not been clearly established.

\section{CONCLUSION}

In localised prostate cancer, LN status is an important prognostic parameter which is used to risk stratify patients for adjuvant treatment. PLND currently represents the most reliable method of nodal staging ${ }^{1}$ and may also have therapeutic benefit. $^{67}$ The pathological examination of PLND specimens plays a crucial role in accurate LN staging, however consensus guidelines regarding the optimal approach are currently lacking. Although certain aspects may require subjective interpretation, a more consistent approach to the pathological handling of PLND specimens will ensure accurate nodal staging for the individual patient and better facilitate the use of average nodal yields as a quality parameter of staging adequacy across institutions. In this regard, collaboration and communication between surgeons and pathologists is essential. Pathologists should also be aware of the potential for LN metastases within AFP specimens so that these are handled appropriately. Although the current TNM staging system does not substratify LN-positive patients, histopathological parameters of prognostic significance such as the size of the largest metastatic deposit should be routinely reported. Future advances in less invasive methods of nodal staging and the use of ancillary techniques including molecular studies may further improve the detection and risk stratification of $\mathrm{LN}$-positive patients.

\section{Take home messages}

- There is an urgent need to establish a more consistent and standardised approach to the pathological evaluation of pelvic lymph node dissection (PLND) specimens. This, in tandem with close collaboration between pathologists and surgeons, is essential to develop quality parameters for accurate nodal staging in prostate cancer.

- At present, there are no guidelines regarding the required LN yield following PLND. In the absence of total submission of the tissue, a low yield ( $<10 \mathrm{LNs})$ should always prompt the pathologist to re-evaluate the specimen.

- Anterior fat pad specimens should be processed as potential nodal resections with isolation and submission of palpable LNs.

- Routine reporting of the diameter of the largest nodal metastasis is recommended.

Handling editor Runjan Chetty

Competing interests None declared.

Provenance and peer review Commissioned; internally peer reviewed.

\section{REFERENCES}

1 Mottet N, Bellmunt J, Briers E, et al., members of the EAU Guidelines Panel on Prostate Cancer. EAU-ESTRO-SIOG Guidelines on Prostate Cancer. Edn. presented at the EAU Annual Congress Munich, 2016. ISBN 978-90-79754-98-4.

2 Ghavamian R, Bergstralh EJ, Blute ML, et al. Radical retropubic prostatectomy plus orchiectomy versus orchiectomy alone for $\mathrm{pTxN}+$ prostate cancer: a matched comparison. J Urol 1999;161:1223-7.

3 Messing EM, Manola J, Sarosdy M, et al. Immediate hormonal therapy compared with observation after radical prostatectomy and pelvic lymphadenectomy in men with node-positive prostate cancer. N Engl J Med 1999;341:1781-8.

4 Messing EM, Manola J, Yao J, et al., Eastern Cooperative Oncology Group study EST 3886. Immediate versus deferred androgen deprivation treatment in patients with node-positive prostate cancer after radical prostatectomy and pelvic lymphadenectomy. Lancet Oncol 2006;7:472-9.

5 Abdollah F, Karnes RJ, Suardi N, et al. Impact of adjuvant radiotherapy on survival of patients with node-positive prostate cancer. J Clin Oncol 2014;32:3939-47.

6 Seiler R, Studer UE, Tschan K, et al. Removal of limited nodal disease in patients undergoing radical prostatectomy: long-term results confirm a chance for cure. J Urol 2014;191:1280-5.

7 Briganti A, Blute ML, Eastham JH, et al. Pelvic lymph node dissection in prostate cancer. Eur Urol 2009;55:1251-65.

8 Daneshmand S, Quek ML, Stein JP, et al. Prognosis of patients with lymph node positive prostate cancer following radical prostatectomy: long-term results. J Urol 2004; 172:2252-5.

9 Pierorazio PM, Gorin MA, Ross AE, et al. Pathological and oncologic outcomes for men with positive lymph nodes at radical prostatectomy: The Johns Hopkins Hospital 30-year experience. Prostate 2013;73:1673-80.

10 Cheng L, Zincke $\mathrm{H}$, Blute ML, et al. Risk of prostate carcinoma death in patients with lymph node metastasis. Cancer 2001;91:66-73.

11 Briganti A, Larcher A, Abdollah F, et al. Updated nomogram predicting lymph node invasion in patients with prostate cancer undergoing extended pelvic lymph node dissection: the essential importance of percentage of positive cores. Eur Urol 2012;61:480-7.

12 Dell'Oglio P, Abdollah F, Suardi N, et al. External validation of the European association of urology recommendations for pelvic lymph node dissection in patients treated with robot-assisted radical prostatectomy. J Endourol 2014;28:416-23.

13 Hinev Al, Anakievski D, Kolev NH, et al. Validation of nomograms predicting lymph node involvement in patients with prostate cancer undergoing extended pelvic lymph node dissection. Urol Int 2014;92:300-5.

14 Godoy G, Chong KT, Cronin A, et al. Extent of pelvic lymph node dissection and the impact of standard template dissection on nomogram prediction of lymph node involvement. Eur Urol 2011;60:195-201.

15 Eden CG, Arora A, Rouse P. Extended vs standard pelvic lymphadenectomy during laparoscopic radical prostatectomy for intermediate- and high-risk prostate cancer. BJU Int 2010;106:537-42. 
16 Heidenreich A, Varga Z, Von Knobloch R. Extended pelvic lymphadenectomy in patients undergoing radical prostatectomy: high incidence of lymph node metastasis. J Urol 2002;167:1681-6.

17 Schumacher MC, Burkhard FC, Thalmann GN, et al. Is pelvic lymph node dissection necessary in patients with a serum $P S A<10 \mathrm{ng} / \mathrm{ml}$ undergoing radical prostatectomy for prostate cancer? Eur Urol 2006;50:272-9.

18 Briganti A, Chun FK, Salonia A, et al. Critical assessment of ideal nodal yield at pelvic lymphadenectomy to accurately diagnose prostate cancer nodal metastasis in patients undergoing radical retropubic prostatectomy. Urology 2007;69:147-51.

19 Touijer K, Rabbani F, Otero JR, et al. Standard versus limited pelvic lymph node dissection for prostate cancer in patients with a predicted probability of nodal metastasis greater than 1\%. J Urol 2007;178:120-4.

20 Yuh BE, Ruel NH, Mejia R, et al. Standardized comparison of robot-assisted limited and extended pelvic lymphadenectomy for prostate cancer. BJU Int 2013;112:81-8.

21 Joniau S, Van den Bergh $\mathrm{L}$, Lerut $\mathrm{E}$, et al. Mapping of pelvic lymph node metastases in prostate cancer. Eur Urol 2013;63:450-8.

22 Mattei A, Fuechsel FG, Bhatta Dhar N, et al. The template of the primary lymphatic landing sites of the prostate should be revisited: results of a multimodality mapping study. Eur Urol 2008;53:118-25.

23 Wawroschek F, Vogt $H$, Weckermann $D$, et al. The sentinel lymph node concept in prostate cancer-first results of gamma probe-guided sentinel lymph node identification. Eur Urol 1999:36:595-600.

24 Bianchi L, Gandaglia G, Fossati N, et al. Pelvic lymph node dissection in prostate cancer: indications, extent and tailored approaches. Urologia 2015. Published Online First: 16 December 2015. doi:10.5301/uro.5000139

25 Acar C, Kleinjan GH, van den Berg NS, et al. Advances in sentinel node dissection in prostate cancer from a technical perspective. Int J Urol 2015;22:898-909.

26 Holl G, Dorn $\mathrm{R}$, Wengenmair $\mathrm{H}$, et al. Validation of sentinel lymph node dissection in prostate cancer: experience in more than 2,000 patients. Eur J Nucl Med Mol Imaging 2009;36:1377-82.

27 Winter A. Editorial Comment to Advances in sentinel node dissection in prostate cancer from a technical perspective. Int J Urol 2015:22:909-10.

28 Borley N, Fabrin K, Sriprasad S, et al. Laparoscopic pelvic lymph node dissection allows significantly more accurate staging in "high-risk" prostate cancer compared to MRI or CT. Scand J Urol Nephrol 2003;37:382-6.

29 Barth PJ, Gerharz EW, Ramaswamy A, et al. The influence of lymph node counts on the detection of pelvic lymph node metastasis in prostate cancer. Pathol Res Pract 1999;195:633-6.

30 Abdollah F, Sun M, Thuret R, et al. Lymph node count threshold for optimal pelvic lymph node staging in prostate cancer. Int J Urol 2012;19:645-51.

31 Weingärtner K, Ramaswamy A, Bittinger A, et al. Anatomical basis for pelvic lymphadenectomy in prostate cancer: results of an autopsy study and implications for the clinic. J Urol 1996;156:1969-71.

32 Davies JD, Simons CM, Ruhotina N, et al. Anatomic basis for lymph node counts as measure of lymph node dissection extent: a cadaveric study. Urology 2013:81:358-63.

33 Kluth LA, Abdollah F, Xylinas E, et al. Pathologic nodal staging scores in patients treated with radical prostatectomy: a postoperative decision tool. Eur Urol 2014;66:439-46.

34 Kluth LA, Abdollah F, Xylinas $E$, et al. Clinical nodal staging scores for prostate cancer: a proposal for preoperative risk assessment. Br J Cancer 2014;111:213-19.

35 Berney DM, Wheeler TM, Grignon DJ, et al., ISUP Prostate Cancer Group. International Society of Urological Pathology (ISUP) Consensus Conference on Handling and Staging of Radical Prostatectomy Specimens. Working group 4: seminal vesicles and lymph nodes. Mod Pathol 2011:24:39-47.

36 Bochner BH, Herr HW, Reuter VE. Impact of separate versus en bloc pelvic lymph node dissection on the number of lymph nodes retrieved in cystectomy specimens. J Urol 2001;166:2295-6.

37 Koren $\mathrm{R}$, Paz A, Lask D, et al. Lymph-node revealing solution: a new method for detecting minute lymph nodes in cystectomy specimens. Br J Urol 1997;80:40-3.

38 Alexander RE, Sung MT, Cheng L. Lymphadenectomy in urologic oncology: pathologic considerations. Urol Clin North Am 2011;38:483-95.

39 Tiguert R, Gheiler EL, Tefilli MV, et al. Lymph node size does not correlate with the presence of prostate cancer metastasis. Urology 1999;53:367-71.

40 Perry-Keene J, Ferguson P, Samaratunga $H$, et al. Total submission of pelvic lymphadenectomy tissues removed during radical prostatectomy for prostate cancer increases lymph node yield and detection of micrometastases. Histopathology 2014;64:399-404.

41 Perry-Keene J, Ferguson $P$, Samaratunga $H$, et al. Effective maybe, but is it cost-effective? A reply. Histopathology 2014;65:729-30.

42 Montironi R, Scarpelli M, Galosi AB, et al. Total submission of lymphadenectomy tissues removed during radical prostatectomy for prostate cancer: possible clinical significance of large-format histology. Hum Pathol 2014;45:2059-62.

43 Oxley J, Varma M, Berney D. Standards and datasets for reporting cancers. Dataset for histopathology reports for prostatic carcinoma. June 2016. http://www.rcpath.org (accessed 1 Jul 2015)

44 Srigley JR, Humphrey PA, Amin MB, et al. For the Members of the Cancer Committee, College of American Pathologists Protocol for the Examination of
Specimens from Patients with Carcinoma of the Prostate Gland. June 2012. http:// www.cap.org (accessed 1 Jul 2015).

45 Epstein JI, Oesterling JE, Eggleston JC, et al. Frozen section detection of lymph node metastases in prostatic carcinoma: accuracy in grossly uninvolved pelvic lymphadenectomy specimens. J Urol 1986;136:1234-7.

46 Engel J, Bastian PJ, Baur $\mathrm{H}$, et al. Survival benefit of radical prostatectomy in lymph node-positive patients with prostate cancer. Eur Urol 2010;57:754-61.

47 Steuber T, Budäus L, Walz J, et al. Radical prostatectomy improves progression-free and cancer-specific survival in men with lymph node positive prostate cancer in the prostate-specific antigen era: a confirmatory study. BJU Int 2011;107:1755-61.

48 Sobin LH, Gospodariwicz M, Wittekind C. TNM classification of malignant tumors International Union Against Cancer (UICC). 7th edn. Oxford, UK: Wiley-Blackwell, 2009.

49 Boorjian SA, Thompson RH, Siddiqui S, et al. Long-term outcome after radical prostatectomy for patients with lymph node positive prostate cancer in the prostate specific antigen era. J Urol 2007;178:864-70.

50 Schumacher MC, Burkhard FC, Thalmann GN, et al. Good outcome for patients with few lymph node metastases after radical retropubic prostatectomy. Eur Urol 2008;54:344-52

51 Briganti A, Karnes JR, Da Pozzo LF, et al. Two positive nodes represent a significant cut-off value for cancer specific survival in patients with node positive prostate cancer. A new proposal based on a two-institution experience on 703 consecutive $\mathrm{N}+$ patients treated with radical prostatectomy, extended pelvic lymph node dissection and adjuvant therapy. Eur Urol 2009;55:261-70.

52 Carlsson SV, Tafe LJ, Chade DC, et al. Pathological features of lymph node metastasis for predicting biochemical recurrence after radical prostatectomy for prostate cancer. J Urol 2013;189:1314-18.

53 Passoni NM, Fajkovic $H$, Xylinas $E$, et al. Prognosis of patients with pelvic lymph node (LN) metastasis after radical prostatectomy: value of extranodal extension and size of the largest LN metastasis. BJU Int 2014;114:503-10.

54 Cheng L, Pisansky TM, Ramnani DM, et al. Extranodal extension in lymph node-positive prostate cancer. Mod Pathol 2000;13:113-18.

55 Cheng L, Bergstralh EJ, Cheville JC, et al. Cancer volume of lymph node metastasis predicts progression in prostate cancer. Am J Surg Pathol 1998;22:1491-500.

56 Boormans JL, Wildhagen MF, Bangma $\mathrm{CH}$, et al. Histopathological characteristics of lymph node metastases predict cancer-specific survival in node-positive prostate cancer. BJU Int 2008;102:1589-93.

57 Fleischmann A, Schobinger $S$, Schumacher $M$, et al. Survival in surgically treated, nodal positive prostate cancer patients is predicted by histopathological characteristics of the primary tumor and its lymph node metastases. Prostate 2009;69:352-62.

58 Cheng L, Montironi R, Bostwick DG, et al. Staging of prostate cancer. Histopathology 2012;60:87-117.

59 Conti A, Santoni M, Burattini L, et al. Update on histopathological evaluation of lymphadenectomy specimens from prostate cancer patients. World J Urol 2015 Published Online First: 22 December 2015. doi:10.1007/s00345-015-1752-8

60 Griebling TL, Ozkutlu D, See WA, et al. Prognostic implications of extracapsular extension of lymph node metastases in prostate cancer. Mod Pathol 1997; 10:804-9.

61 Fleischmann A, Schobinger S, Markwalder R, et al. Prognostic factors in lymph node metastases of prostatic cancer patients: the size of the metastases but not extranodal extension independently predicts survival. Histopathology 2008;53:468-75.

62 Hofer MD, Kuefer R, Huang $W$, et al. Prognostic factors in lymph node-positive prostate cancer. Urology 2006;67:1016-21.

63 Cheng L, Slezak J, Bergstralh EJ, et al. Dedifferentiation in the metastatic progression of prostate carcinoma. Cancer 1999;86:657-63.

64 Engvad B, Poulsen MH, Staun PW, et al. Histological step sectioning of pelvic lymph nodes increases the number of identified lymph node metastases. Virchows Arch 2014:464:45-52

65 Pagliarulo V, Hawes D, Brands FH, et al. Detection of occult lymph node metastases in locally advanced node-negative prostate cancer. J Clin Oncol 2006;24:2735-42.

66 Wawroschek F, Wagner T, Hamm M, et al. The influence of serial sections, immunohistochemistry, and extension of pelvic lymph node dissection on the lymph node status in clinically localized prostate cancer. Eur Urol 2003;43:132-6.

67 Schilling D, Hennenlotter J, Sotlar K, et al. Quantification of tumor cell burden by analysis of single cell lymph node disaggregates in metastatic prostate cancer. Prostate 2010;70:1110-18.

68 Schilling D, Hennenlotter J, Gakis G, et al. Prospective assessment of histological serial sectioning of pelvic lymph nodes in prostate cancer: a cost-benefit analysis. BJU Int 2012;110(Pt B):E166-71.

69 Clobes H, Fossâ SD, Waehre $H$, et al. The immunohistochemical assessment of occult regional lymph node metastases in patients with T3pNOMO prostate cancer before definitive radiotherapy. BJU Int 2000;85:270-5.

70 Kehr E, Masry $P$, Lis $R$, et al. Detecting metastatic prostate carcinoma in pelvic lymph nodes following neoadjuvant hormone therapy: the eyes have it! Histopathology 2016;68:303-7.

71 Ferrari AC, Stone NN, Kurek R, et al. Molecular load of pathologically occult metastases in pelvic lymph nodes is an independent prognostic marker of 
biochemical failure after localized prostate cancer treatment. J Clin Oncol 2006;24:3081-8.

72 Schiavina R, Capizzi E, Borghesi M, et al. Nodal occult metastases in intermediate- and high-risk prostate cancer patients detected using serial section, immunohistochemistry, and real-time reverse transcriptase polymerase chain reaction: prospective evaluation with matched-pair analysis. Clin Genitourin Cancer 2015;13:e55-64.

73 Tsaur I, Hennenlotter J, Oppermann E, et al. PCA3 and PSA gene activity correlates with the true tumor cell burden in prostate cancer lymph node metastases. Cancer Biomark 2015;15:311-16.

74 Miyake $\mathrm{H}$, Kurahashi $\mathrm{T}$, Hara I, et al. Significance of micrometastases in pelvic lymph nodes detected by real-time reverse transcriptase polymerase chain reaction in patients with clinically localized prostate cancer undergoing radical prostatectomy after neoadjuvant hormonal therapy. BJU Int 2007:99:315-20.

75 Schostak M, Krause $\mathrm{H}$, Miller $\mathrm{K}$, et al. Does the molecular staging in pelvic lymph nodes improve the detection of relevant prostate cancer metastases? An assessment after 6 years. BJU Int 2007;99:1409-14.

76 Ahlering TE, Eichel L, Edwards RA, et al. Robotic radical prostatectomy: a technique to reduce pT2 positive margins. Urology 2004;64:1224-8.

77 Aning JJ, Thurairaja R, Gillatt DA, et al. Pathological analysis of lymph nodes in anterior prostatic fat excised at robot-assisted radical prostatectomy. I Clin Pathol 2014:67:787-91.
78 Yuh $\mathrm{B}, \mathrm{Wu} \mathrm{H}$, Ruel $\mathrm{N}$, et al. Analysis of regional lymph nodes in periprostatic fat following robot-assisted radical prostatectomy. BJU Int 2012;109:603-7.

79 Finley DS, Deane L, Rodriguez E, et al. Anatomic excision of anterior prostatic fat at radical prostatectomy: implications for pathologic upstaging. Urology 2007;70:1000-3.

80 Jeong J, Choi EY, Kang DI, et al. Pathologic implications of prostatic anterior fat pad. Urol Oncol 2013;31:63-7.

81 Kim IY, Modi PK, Sadimin E, et al. Detailed analysis of patients with metastasis to the prostatic anterior fat pad lymph nodes: a multi-institutional study. J Urol 2013;190:527-34.

82 Hansen J, Budäus L, Spethmann J, et al. Assessment of rates of lymph nodes and lymph node metastases in periprostatic fat pads in a consecutive cohort treated with retropubic radical prostatectomy. Urology 2012;80:877-82.

83 Deng FM, Mendrinos SE, Das K, et al. Periprostatic lymph node metastasis in prostate cancer and its clinical significance. Histopathology 2012;60:1004-8.

84 Kothari PS, Scardino PT, Ohori M, et al. Incidence, location, and significance of periprostatic and periseminal vesicle lymph nodes in prostate cancer. Am J Surg Pathol 2001;25:1429-32.

85 González-Roibón N, Han JS, Lee S, et al. Comparison of biochemical recurrence-free survival between periprostatic and pelvic lymph node metastases of prostate cancer. Int I Surg Pathol 2013;21:352-7. 